\title{
Hepcidin and Iron Metabolism in Pregnancy: Correlation with Smoking and Birth Weight and Length
}

\author{
Magdalena Chełchowska ${ }^{1}$ - Jadwiga Ambroszkiewicz ${ }^{1}$ Joanna Gajewska ${ }^{1}$. \\ Ewa Jabłońska-Głąb ${ }^{1}$ • Tomasz M. Maciejewski ${ }^{2} \cdot$ Mariusz Oltarzewski $^{1}$
}

Received: 17 November 2015 / Accepted: 5 January 2016 / Published online: 20 January 2016

(C) The Author(s) 2016. This article is published with open access at Springerlink.com

\begin{abstract}
To estimate the effect of tobacco smoking on iron homeostasis and the possible association between hepcidin and the neonatal birth weight and length, concentrations of serum hepcidin and selected iron markers were measured in 81 healthy pregnant women ( 41 smokers and 40 nonsmokers). The smoking mothers had significantly lower concentrations of serum hepcidin $(p<0.001)$, iron $(p<0.001)$, and hemoglobin $(p<0.05)$, but higher erythropoietin $(p<0.05)$ levels compared with non-smoking pregnant women. Logistic regression analysis showed the highest negative impact of the number of cigarettes smoked per day $(\beta=-0.46 ; p<0.01)$ and positive impact of ferritin level $(\beta=0.47 ; p<0.001)$ on serum hepcidin concentration. The birth weight and the body length of smoking mothers' infants were significantly lower than in tobacco abstinent group $(p<0.001)$. In multiple regression analysis, birth body weight $(\beta=0.56 ; p<0.001)$ and length $(\beta=0.50 ; p<0.001)$ were significantly related to maternal hepcidin values. Tobacco smoking affected hepcidin level in serum of pregnant women in a dose-dependent manner. Low concentrations of iron and hemoglobin in maternal serum coexisting with high level of erythropoietin suggest that smoking could lead to subclinical iron deficiency and chronic hypoxia not only in mothers but also in fetus. Low serum hepcidin concentration in smoking pregnant women might be associated with lower fetal birth weight and length.
\end{abstract}

Magdalena Chełchowska

magdalena.chelchowska@imid.med.pl

1 Screening Department, Institute of Mother and Child, Kasprzaka 17a, 01-211 Warsaw, Poland

2 Department of Obstetrics and Gynecology, Institute of Mother and Child, Kasprzaka 17a, 01-211 Warsaw, Poland
Keywords Hepcidin · Tobacco smoking · Pregnancy · Birth body weight $\cdot$ Birth body length

\section{Introduction}

Iron deficiency during pregnancy continues to be a common clinical problem and is one of the most prevalent nutritional deficits both in the industrial and developing countries. Iron requirements increase significantly (near 10-fold) over gestation; therefore, pregnant women are particularly at risk of developing iron deficiency anemia. The prevalence of anemia is dependent on nutritional status and use of sufficient prenatal supplements and ranges from 14 to $52 \%$ women who are not taking prenatal supplements, to $0-25 \%$ among pregnant women receiving regular multivitamin (containing iron and folic acid) preparation [1-5].

In the last decade, much attention was paid to research on new markers involved in the regulation of iron homeostasis [4, 6]. Hepcidin, a 25-amino-acids peptide hormone (Hep-25), has recently emerged as a key regulator of iron homeostasis. Apart from main synthesis in the liver, hepcidin messenger RNA (mRNA) is also expressed in the lung, heart, brain, and placenta tissue. Hepcidin regulates intestinal absorption, macrophage release, and the placental passage of iron. This hormone inhibits the cellular efflux of iron by binding to and inducing the degradation of ferroportin, the only known cellular iron exporter [7]. The role of hepcidin in the regulation of iron metabolism in pregnancy and its effects on the fetus and consequently on the newborn is not fully understood. Rising iron requirements in subsequent trimesters of pregnancy, in both the mother and the fetus, induces an increase in maternal dietary iron absorption and increase iron flux to the fetus via placenta $[1,2]$. In utero-placenta unit, hepcidin causing degradation of syncytiotrophoblast ferroportin regulates iron 
release into the fetal circulation $[8,9]$. Hepcidin expression is induced by iron overload and inflammation and is suppressed by anemia, erythropoietic activity, and hypoxia [10, 11]. Iron deficiency in pregnant women is assumed to be enhanced by cigarette smoking [12,13]. Despite the fact that in the last years, a decrease in the number of active smokers has been observed and knowledge of the adverse health effect of smoking during pregnancy is quite common, $25-30 \%$ pregnant women in Poland continue smoking $[14,15]$. Tobacco smoking is associated in dose-related manner with stimulation of erythropoiesis due to increased maternal and fetal iron requirements probably through a hypoxic effect [16-18]. It is suggested that accompanying smoking hypoxia can suppress hepcidin mRNA expression and reduces hepcidin concentration in pregnant women as well as in newborns.

The aim of the study was to estimate the effect of tobacco smoking on serum hepcidin and selected iron parameters in pregnant women. We evaluated relationships between hepcidin and other indicators of iron status. Furthermore, we investigated the possible association between serum hepcidin concentration and the neonatal birth weight and length.

\section{Methods}

\section{Patients}

Two groups of women were taken from a prospective observational study for adverse effects of tobacco smoking in pregnant women visiting the Department of Obstetrics and Gynecology, Institute of Mother and Child, Warsaw, Poland, between January 2013 and March 2015. The study was conducted according to the principles of the Declaration of Helsinki and was approved by the Ethics Committee of the Institute of Mother and Child. All pregnant volunteers were made aware of the study objectives and informed written consent was obtained for analysis of biological samples and linking results to the data collected from questionnaires.

The base study population, wherein the present study was nested, constituted 296 singleton pregnancies. In the study group, 41 cases were included which had hospital visits in the third trimester of pregnancy (32-36 weeks) and continued smoking during pregnancy (minimum five cigarettes per day and minimum 2 years before conception). The control group consisted of 40 non-smoking, healthy pregnant women similar to age and gestational age. Gestational age was estimated by the last menstrual period and confirmed or corrected by ultrasonographic measurements of the crown-rump length (dated in the first trimester). The groups included only women with a single physiological pregnancy who, before pregnancy, had normal menstrual cycles, were in good health at time of examination, and declared good living conditions. The exclusion criteria for the study were maternal diseases (preeclampsia, hypertension, diabetes mellitus, active hepatitis, renal and cardiovascular diseases, and inflammatory conditions), multiple pregnancy, birth defects detected during pregnancy, alcohol drinking, and assisted reproduction. Women exposed to second-hand smoke (smoking spouse or other family members, co-workers) were excluded from the tobacco abstinent group. The classification of groups was confirmed by measurement of serum cotinine- the major metabolite of nicotine in pregnant women. A cutoff value of $\geq 13.7 \mu \mathrm{g} / \mathrm{L}$ was used to separate smokers from nonsmokers, in accordance with others studies [19]. All subjects in our study reported taking standard vitamins with iron and folate during pregnancy (average $400-800 \mu \mathrm{g}$ of folate, $15-60 \mathrm{mg}$ of ferrous fumarate daily).

After birth, clinical information on the infants, including weight and body length, were collected.

\section{Collection and Analysis of Blood Samples}

Maternal peripheral blood samples $(5 \mathrm{~mL})$ were taken at the time of recruitment (30-34 weeks of gestation). In order to obtain serum, the blood was centrifuge at $2500 \times g$ at $4{ }^{\circ} \mathrm{C}$ for $10 \mathrm{~min}$ and was stored in small portions at $-25^{\circ} \mathrm{C}$ for subsequent biochemical analysis.

Serum hepcidin, erythropoietin (EPO), and soluble transferrin receptor (sTfR) values were determined by immunoassay (DRG, Marburg Mediagnost, Reutlingen, Germany). The limit of detection was $0.35 \mathrm{ng} / \mathrm{mL}$ for hepcidin, $1.1 \mathrm{mIU} / \mathrm{mL}$ for EPO, and $2 \mathrm{ng} / \mathrm{mL}$ for sTfR, respectively. The intra- and inter-assay coefficients of variation were less than 3.3 and $11.5 \%$ for hepcidin, 8.4 and $8.8 \%$ for EPO, and 6.0 and $7.0 \%$ for sTfR, respectively.

Serum levels of iron $(\mathrm{Fe})$, ferritin $(\mathrm{Ft})$, transferrin $(\mathrm{Tf})$, and C-reactive protein (CRP) were measured by standard methods using commercially available kits on COBAS INTEGRA analyzer (Roche, Switzerland). Concentration of hemoglobin (Hgb) in blood was determined using commercially available kits on Pentra 60 hematology analyzer (HORRIBA ABX, France).

Cotinine levels in serum were evaluated by immunoenzymatic method using a commercially available kit Cotinine one-step ELISA (Calbiotech Inc., Spring Valley, CA, USA).

Pre-pregnancy body mass index (BMI) was calculated using height and pre-pregnancy weight. Newborn infants were examined in the first $24 \mathrm{~h}$ of life. Neonatal length and weight were determined using a measuring board to the nearest $0.1 \mathrm{~cm}$ and a calibrated scale to the nearest $10 \mathrm{~g}$.

\section{Statistical Analysis}

Statistical analysis was performed using STATISTICA 10.0 (StatSoft, Poland) software. Data were presented as mean 
values and standard deviation (SD) for normal distribution or median value and interquartile range (25th-75th percentiles) for skewed distribution. The Shapiro-Wilk test was used for evaluation normality of data distribution prior to statistical analysis. Group differences were determined by Student's $t$ test or Mann-Whitney test depending on the assumptions. The chi-square test was used for comparing nominal variables. For simple correlation analysis, Pearson or Spearman correlation coefficients were calculated. Linear regression models with concentration of hepcidin as a dependent variable were estimated in the separate sample of smokers to examine the potential impact of some iron parameters, number of the cigarettes per day, and cotinine level. To evaluate relationships between anthropometric parameters and studied iron markers, multivariate linear regression models with body birth weight and body birth length as dependent variables were estimated (adjusted for gender and smoking status).

Results were expressed as the value of $\beta$ standardized regression coefficient and its significance together with coefficient of determination $R$-squared expressed as the percent of the variation that can be explained by regression equation. A $p$ value less than 0.05 was considered statistically significant.

\section{Results}

Table 1 presents the clinical characteristics and biochemical measurements of the 81 participants who completed the study. Maternal clinical characteristics parameters were comparable in both groups except for cigarette smoking habits. In the group of smoking mothers, the mean number of cigarettes per day was 8.8, the mean duration of smoking before conception was 8.6 years, and the mean serum cotinine concentration was $86.5 \mu \mathrm{g} / \mathrm{L}$. In the tobacco abstinent group, serum cotinine was present only in trace amounts. There were no severe complications during delivery in either group. Mean birth weight, body length, and head circumference of the smoking mothers' infants were significantly lower ( $p<0.001 ; p<0.01 ; p<0.001$, respectively) compared with that of the abstinent group. Apgar score was similar in the two groups. According to biochemical markers, the smoking mothers had significantly lower concentrations of serum hepcidin $(p<0.001)$, iron $(p<0.01)$, and hemoglobin $(p<0.05)$, but higher erythropoietin levels $(p<0.05)$ compared with nonsmoking pregnant women. The levels of ferritin, soluble transferrin receptor, and C-reactive protein were similar in both groups.

In smoking pregnant women group, hepcidin was negatively related to the number of cigarettes per day $(p<0.01)$, cotinine $(p<0.05)$, EPO $(p<0.05)$, and STfR $(p<0.05)$ in linear regression analysis. On the contrary, hepcidin was positively related to $\mathrm{Ft}(p<0.001)$ and $\mathrm{Hgb}(p<0.05)$. We did not observe significant correlations between hepcidin and iron as well as transferrin. Hepcidin was not related to $\mathrm{C}$ reactive protein-marker of acute phase inflammation (Table 2).

Correlation studies revealed that birth weight and birth length in infants of smokers were negatively related with serum cotinine and number of cigarettes smoked per day. The relationship between hepcidin concentration and anthropometric parameters was observed in both groups. Additionally, birth body weight was positively correlated with iron and hemoglobin levels only in the group of tobacco abstinent, whereas birth body length correlated negatively with erythropoietin only in the smoking group (Table 3 ).

In multi-variable regression model defined for the whole group, adjusted for gender and smoking status, birth body weight was associated with serum hepcidin $(\beta=0.559$, $p=0.000)$ and iron $(\beta=0.240, p=0.008)$ but not hemoglobin $(\beta=-0.105, p=0.314)$. For birth body length, the highest impact of the serum hepcidin concentration was indicated ( $\beta=0.496, p=0.000)$. Markers of estimated intensity of cigarette smoking and ferritin concentration were not included in the same multi-variable model because these parameters and hepcidin were highly dependent $\left(R^{2}=21.5 \%\right.$ for number of cigarettes per day, $R^{2}=14.5 \%$ for cotinine, $R^{2}=22.5 \%$ for ferritin).

\section{Discussion}

Research on the relationship between smoking during pregnancy and total body iron stores has been conducted for many years, but corresponding literature data are still fragmentary and the results are controversial. No effect of smoking on iron homeostasis parameters during gestation was reported; however, some investigators observed a tendency to decrease concentrations of hemoglobin, hematocrite, and iron with longer smoke exposition and more cigarettes smoked per day [12, 15, 20, 21]. Our findings showed that hemoglobin and iron levels were significantly lower in the smoking group than in the tobacco abstinent. The same results were described by Rasmussen et al. [13] and Zafar et al. [22] who suggested that iron supplementation through pregnancy had a higher relative increase in hemoglobin concentration toward the end of pregnancy. In the case of transferrin, soluble transferrin receptor, and ferritin concentrations, we did not identify differences between the studied groups. This is consistent with other's previous research where no significant relation between concentration of ferritin and smoking was found [13]. On the contrary, some studies showed higher levels of ferritin in pregnant women who smoke [18, 23]. This 
Table 1 Clinical characteristics and biochemical measurements in smoking and non-smoking pregnant women $(n=81)$

\begin{tabular}{|c|c|c|c|}
\hline Characteristic & Smoking $(n=41)$ & Non-smoking $(n=40)$ & $p$ value \\
\hline Maternal age (years) ${ }^{\mathrm{a}}$ & $28.8 \pm 4.5$ & $30.3 \pm 4.8$ & 0.120 \\
\hline Ethnic origin: Caucasian $(\%)^{\mathrm{c}}$ & 100 & 100 & - \\
\hline Maternal weight $(\mathrm{kg})^{\mathrm{a}}$ & $63.9 \pm 5.2$ & $65.6 \pm 5.4$ & 0.123 \\
\hline Maternal height $(\mathrm{cm})^{\mathrm{a}}$ & $165.1 \pm 0.1$ & $165.0 \pm 0.1$ & 0.884 \\
\hline Pre-gravid BMI $\left(\mathrm{kg} / \mathrm{m}^{2}\right)^{\mathrm{a}}$ & $23.4 \pm 1.3$ & $24.1 \pm 1.4$ & 0.073 \\
\hline Gestational age of delivery (weeks) $^{\mathrm{b}}$ & $39[39-40]$ & $39[39-40]$ & 0.384 \\
\hline Delivery: cesarean/vaginal $(\%)^{\mathrm{c}}$ & $4.9 / 95.1$ & $2.5 / 97.5$ & 0.571 \\
\hline Neonatal gender female/male $(\%)^{\mathrm{c}}$ & $46 / 54$ & $38 / 62$ & 0.420 \\
\hline \multicolumn{4}{|l|}{ Birth weight $(\mathrm{g})^{\mathrm{a}}$} \\
\hline Whole group & $3123.7 \pm 426.4$ & $3516.6 \pm 445.6$ & 0.000 \\
\hline Male & $3160.5 \pm 388.7$ & $3647.2 \pm 399.2$ & 0.000 \\
\hline Female & $3081.1 \pm 473.6$ & $3298.7 \pm 445.6$ & 0.182 \\
\hline \multicolumn{4}{|l|}{ Birth body length $(\mathrm{cm})^{\mathrm{a}}$} \\
\hline Whole group & $54.4 \pm 2.7$ & $55.9 \pm 2.5$ & 0.009 \\
\hline Male & $54.6 \pm 3.0$ & $56.6 \pm 2.4$ & 0.010 \\
\hline Female & $54.1 \pm 3.0$ & $54.8 \pm 2.3$ & 0.431 \\
\hline \multicolumn{4}{|l|}{ Head circumference $(\mathrm{cm})^{\mathrm{a}}$} \\
\hline Whole group & $34.0 \pm 1.7$ & $35.0 \pm 1.1$ & 0.000 \\
\hline Male & $34.3 \pm 1.1$ & $35.2 \pm 1.0$ & 0.003 \\
\hline Female & $33.7 \pm 1.3$ & $34.7 \pm 1.1$ & 0.033 \\
\hline Apgar score $(5 \text { th } \min )^{\mathrm{b}}$ & $10[10-10]$ & $10[10-10]$ & 0.576 \\
\hline Number of cigarettes/day ${ }^{b}$ & $10[5-10]$ & 0 & - \\
\hline Time of smoking before conception (year) ${ }^{b}$ & $8[5-12]$ & 0 & - \\
\hline Cotinine $(\mu \mathrm{g} / \mathrm{L})^{\mathrm{b}}$ & $87.9[58.1-108.5]$ & 0 & - \\
\hline Hepcidin $(\mathrm{ng} / \mathrm{mL})^{\mathrm{a}}$ & $10.9 \pm 6.8$ & $16.3 \pm 6.8$ & 0.000 \\
\hline $\mathrm{EPO}(\mathrm{mIU} / \mathrm{mL})^{\mathrm{b}}$ & $17.6[12.5-32.7]$ & $14.4[12.2-21.3]$ & 0.037 \\
\hline $\mathrm{Ft}(\mathrm{ng} / \mathrm{mL})^{\mathrm{b}}$ & $11.5[8.5-15.7]$ & $13.5[8.8-30.4]$ & 0.170 \\
\hline $\mathrm{Fe}(\mu \mathrm{mol} / \mathrm{L})^{\mathrm{a}}$ & $12.0 \pm 4.5$ & $16.4 \pm 7.0$ & 0.001 \\
\hline $\operatorname{Hgb}(g / d L)^{a}$ & $12.2 \pm 1.1$ & $12.7 \pm 1.1$ & 0.049 \\
\hline $\operatorname{sTfR}(\mu \mathrm{g} / \mathrm{mL})^{\mathrm{b}}$ & $1.3[1.2-1.7]$ & $1.1[1.0-1.6]$ & 0.161 \\
\hline $\operatorname{Tf}(\mathrm{mg} / \mathrm{dL})^{\mathrm{a}}$ & $417.7 \pm 65.1$ & $400.1 \pm 82.1$ & 0.208 \\
\hline $\operatorname{CRP}(\mathrm{nmol} / \mathrm{L})^{\mathrm{a}}$ & $59.0 \pm 17.1$ & $56.2 \pm 16.2$ & 0.549 \\
\hline
\end{tabular}

$B M I$ body mass index, EPO erythropoietin, $F t$ ferritin, $F e$ iron, $H g b$ hemoglobin, sTfR soluble transferrin receptor, $T f$ transferrin, $C R P$ C-reactive protein

${ }^{a}$ Values are means \pm standard deviation (SD)

${ }^{\mathrm{b}}$ Values are median and interquartile range (25th-75th percentiles)

${ }^{\mathrm{c}}$ Values are percentage may be due to the fact that they have been conducted in group of women between 19 and 26 weeks of gestation, while iron deficiency is the highest at the end of pregnancy [23].

There are a few human studies assessing hepcidin during pregnancy [2, 24-31]. Concentration of this hormone in healthy non-smoking pregnant women decreased gradually in the course of pregnancy in order to maximize iron absorption and availability, thus enhancing transfer to the fetus [4, 26-29]. The third trimester values of hepcidin in our study are consistent with the report by Rehu et al. [30] and Young et al. [26] and slightly higher than the report by other investigators $[24,25,31]$. These differences may result from the method applied with hepcidin, selection of the research group, material, gestational age, and type of delivery. Some authors postulated elevated hepcidin at the day of delivery and in women who delivered vaginally in comparison to cesarean section which may be related to inflammatory cytokine activation during labor and the postpartum period [26, 30, 32]. In general, for uncomplicated pregnancies, no relation between 
Table 2 Univariate regression analyses of hepcidin with number of cigarettes per day, serum cotinine concentration, and studied biochemical markers in smoking pregnant women $(n=41)$

\begin{tabular}{lllll}
\hline Independent variables & $\beta$ & SE for $\beta$ & $p$ value & $R^{2} \%$ \\
\hline Number of cigarettes/day & -0.46 & 0.142 & 0.002 & 21.5 \\
Cotinine & -0.38 & 0.148 & 0.014 & 14.5 \\
EPO & -0.25 & 0.109 & 0.027 & 6.1 \\
$\mathrm{Ft}$ & 0.47 & 0.099 & 0.000 & 22.5 \\
$\mathrm{Fe}$ & 0.21 & 0.010 & 0.054 & 4.5 \\
$\mathrm{Hgb}$ & 0.27 & 0.108 & 0.015 & 7.2 \\
$\mathrm{sTfR}$ & -0.25 & 0.109 & 0.024 & 6.2 \\
$\mathrm{Tf}$ & -0.17 & 0.111 & 0.128 & 2.9 \\
$\mathrm{CRP}$ & 0.14 & 0.159 & 0.399 & 1.8 \\
\hline
\end{tabular}

$E P O$ erythropoietin, $F t$ ferritin, $\mathrm{Fe}$ iron, $\mathrm{Hg} b$ hemoglobin, $s T f R$ soluble transferrin receptor, $T f$ transferrin, $C R P$ C-reactive protein

hepcidin level and inflammatory markers during pregnancy was recognized; also our findings are in accordance with these results $[1,25,31]$. Although in both studied group (nonsmoking and smoking pregnant women), the C-reactive protein concentrations were slightly higher than in non-pregnant women, it was in the range of gestational age-specific reference values [5]. Similar to Rehu et al. [30] and Young et al. [26], we measured hepcidin in serum of healthy, non-anemic women using ELISA method which directly detects the biologically active 25 -amino-acid form of this hormone. It is noteworthy that we conducted our study toward the end of the pregnancy and $90 \%$ of births took place vaginally.

To our knowledge, this is the first study to report influence of tobacco smoking on hepcidin in blood of pregnant women.
Previously, we observed a negative effect of smoking on serum pro-hepcidin (pro-hormone) levels during gestation [33]. A recent analysis showed a significant inverse association between hepcidin concentrations and the number of cigarettes per day as well as cotinine levels. Our results confirmed reports observed in groups of non-smoking women regarding the positive association between hepcidin and ferritin as well as hemoglobin during gestation [2, 26-28]. In agreement with Finkenstead et al. [29], also a negative relation between hepcidin and erythropoietin was found. We suggested that accompanying smoking hypoxia can suppress hepcidin mRNA expression reducing this hormone in mothers and probably in newborns. The higher erythropoietin concentration (as indicator of hypoxia) coexisting with lower iron and hemoglobin levels in smoking pregnant women and correlation between this parameter and smoking dose-dependent hepcidin concentration seem to confirm this hypothesis.

As noted in the introduction, hypoxia in smoking people affects not only increased deficiency of iron for erythropoiesis but also oxidative damage depending on the amount of enhanced reactive oxygen species (ROS) generated by tobacco smoke. It is widely accepted that in cigarette smokers, increased oxidative stress is observed, concerning smoking pregnant women [34]. There have been a few in vivo trials documenting the effects of hypoxia on circulating hepcidin level, with only four of those focusing on human. The decreased concentration of this hormone in chronic obstructive pulmonary disease (CODP) patients and in healthy volunteers exposed to hypobaric hypoxia at high altitude was observed $[35,36]$. The remaining two suggested that prenatal, uteroplacental chronic hypoxia reduced pro-hepcidin synthesis in the fetus [37, 38]. Animal models demonstrate that increasing
Table 3 Simple correlations (Spearman or Pearson) between newborn anthropometric parameters and the concentrations of studied biochemical parameters in group of smoking $(n=41)$ and non-smoking $(n=40)$ pregnant women

\begin{tabular}{|c|c|c|c|c|c|c|c|c|}
\hline \multirow[t]{3}{*}{ Biochemical parameters } & \multicolumn{4}{|c|}{ Birth body weight } & \multicolumn{4}{|c|}{ Birth body length } \\
\hline & \multicolumn{2}{|c|}{ Smoking group } & \multicolumn{2}{|c|}{$\begin{array}{l}\text { Non-smoking } \\
\text { group }\end{array}$} & \multicolumn{2}{|c|}{ Smoking group } & \multicolumn{2}{|c|}{$\begin{array}{l}\text { Non-smoking } \\
\text { group }\end{array}$} \\
\hline & $r$ & $p$ value & $r$ & $p$ value & $r$ & $p$ value & $r$ & $p$ value \\
\hline Hepcidin $^{\mathrm{a}}$ & 0.45 & 0.003 & 0.57 & 0.000 & 0.47 & 0.002 & 0.42 & 0.008 \\
\hline $\mathrm{EPO}^{\mathrm{b}}$ & -0.21 & 0.180 & -0.10 & 0.557 & -0.42 & 0.007 & -0.06 & 0.718 \\
\hline $\operatorname{sTf}^{a}$ & -0.13 & 0.427 & -0.06 & 0.708 & -0.22 & 0.175 & 0.03 & 0.849 \\
\hline $\mathrm{Tf}^{\mathrm{a}}$ & 0.07 & 0.685 & -0.25 & 0.117 & -0.07 & 0.659 & -0.18 & 0.266 \\
\hline $\mathrm{Ft}^{\mathrm{b}}$ & 0.22 & 0.163 & 0.30 & 0.064 & 0.19 & 0.233 & -0.01 & 0.967 \\
\hline $\mathrm{Fe}^{\mathrm{a}}$ & 0.14 & 0.393 & 0.31 & 0.049 & 0.20 & 0.205 & 0.13 & 0.420 \\
\hline $\mathrm{Hgb}^{\mathrm{a}}$ & -0.09 & 0.561 & 0.32 & 0.042 & 0.07 & 0.669 & 0.24 & 0.134 \\
\hline Cotinine $^{b}$ & -0.61 & 0.000 & - & - & -0.37 & 0.017 & - & - \\
\hline Number of cigarettes/day ${ }^{\mathrm{b}}$ & -0.54 & 0.000 & - & - & -0.32 & 0.039 & - & - \\
\hline
\end{tabular}

$E P O$ erythropoietin, $s T f R$ soluble transferrin receptor, $T f$ transferrin, $F t$ Ferritin, Fe iron, $H g b$ hemoglobin

${ }^{a}$ Pearson correlation

${ }^{\mathrm{b}}$ Spearman correlation 
reactive oxygen species, especially $\mathrm{H}_{2} \mathrm{O}_{2}$, reduced expression of hepcidin mRNA as well as hepatic iron concentration [39, 40]. However, iron, inflammation, and smoking are also known to drive ROS production, so the interaction of these factors is complex and it is likely to be a balance of all this factors that regulates the final level of hepcidin synthesis in human. Therefore, it is possible that oxidative stress may attenuate the iron and inflammation-induced upregulation of hepcidin, which would lead to a relative lowering of hepcidin and elevated iron absorption [11, 39].

There is a strong evidence that smoking during pregnancy influenced negatively on birth body weight, length, and head circumference [41-43]. Also, maternal iron deficiency anemia (IDA) has been linked to higher risk of low birth, but the detailed mechanisms by which this occurs still remain unclear [44-46]. Hepcidin is involved in active transport of iron through placental syncytiothrophoblast from mother to child. The findings of Young and colleagues [26] indicated that maternal hepcidin at least in part determined fetal iron homeostasis. They showed inverse correlation between maternal hepcidin and the iron transport to the fetus [26]. There have been no studies that describe association between maternal concentrations of hepcidin and birth anthropometric parameters. Some authors reported that cord blood hepcidin level is similar in full-term intrauterine growth-restricted and appropriate-for-gestational-age infants at birth [9]. However, maternal hepcidin concentration was not associated with cord blood hepcidin in a newborn at term [30]. We found that maternal hepcidin could be an important predictor of birth weight and length of full-term newborns in tobacco abstinent as well as in smoking. Maternal smoking is associated with increased fetal iron requirements and stimulates fetal erythropoiesis depending on the degree of exposure to tobacco smoke [16, 46, 47]. Maternal low level of hepcidin and negative iron balance may lead to intrauterine growth retardation as well as low birth weight $[9,30,45]$. Further studies may explain the mechanism by which downregulation of hepcidin by tobacco smoking hypoxia contributes to fetal growth.

Our study is limited by its relatively small sample size; however, both studied groups were similar for ethnicity, gestational age, fetal gender, and type of birth which are recognized as important factors for hepcidin levels [1, 30, 32, 48]. Additionally, we did not measure iron dietary intake, which might influence markers of iron metabolism, but our population consisted of healthy, well-nourished mothers remaining on a mixed diet and receiving regular multivitamin preparation (containing small doses of iron and folic acid) as a part of routine perinatal care. Another limitation is that we have not studied direct effect of tobacco smoking on newborn iron metabolism, and future research should assess maternal and cord blood hepcidin level in a large group of matched maternal cord pairs.

In conclusion, tobacco smoking affected hepcidin level in serum of pregnant women in a dose-dependent manner. Low concentrations of iron and hemoglobin in maternal serum coexisting with high level of erythropoietin suggest that smoking could lead to subclinical iron deficiency and chronic hypoxia not only in mothers but also in fetus. Low serum hepcidin concentration in smoking pregnant women might be associated with lower fetal birth weight and length.

Compliance with Ethical Standards The study was conducted according to the principles of the Declaration of Helsinki and was approved by the Ethics Committee of the Institute of Mother and Child. All pregnant volunteers were made aware of the study objectives and informed written consent was obtained for analysis of biological samples and linking results to the data collected from questionnaires.

Conflict of Interest The authors declare that they have no competing interests.

Open Access This article is distributed under the terms of the Creative Commons Attribution 4.0 International License (http:// creativecommons.org/licenses/by/4.0/), which permits unrestricted use, distribution, and reproduction in any medium, provided you give appropriate credit to the original author(s) and the source, provide a link to the Creative Commons license, and indicate if changes were made.

\section{References}

1. Dawn Koenig M, Tussing-Humphreys L, Day J, Cadwell B, Nemeth E (2014) Hepcidin and iron homeostasis during pregnancy. Nutrients 6:3062-3083

2. Schulze KJ, Christian P, Ruczinski I, Ray AL, Nath A, Wu LS-F, Semba RD (2008) Hepcidin and iron status among pregnant women in Bangladesh. Asia Pac J Clin Nutr 17(3):451-456

3. Sawada T, Konomi A, Yokoi K (2014) Iron deficiency without anemia is associated with anger and fatigue in young Japanese women. Biol Trace Elem Res 159:22-31

4. Cao C, O'Brien KO (2013) Pregnancy and iron homeostasis: an update. Nutr Rev 71(1):35-51

5. Klajnbard A, Szecsi PB, Colov NP, Andersen MR, Jorgensen M, Bjorngaard B, Barfoed A, Haahr K, Stender S (2010) Laboratory reference intervals during pregnancy, delivery and the early postpartum period. Clin Chem Lab Med 48(2):237-248

6. Gantz T (2011) Hepcidin and iron regulation, 10 years later. Blood 117:4425-4433

7. Nemeth E, Tutlle MS, Powelson J, Vaughn MB, Donovan A, Ward DM, Ganz T, Kaplan J (2004) Hepcidin regulates cellular iron efflux by binding to ferroportin and inducing its internalization. Science 306:2090-2093

8. Słomka A, Żekanowska E, Piotrowska K, Kwapisz J (2012) Iron metabolism and maternal-fetal iron circulation. Postepy Hig Med Dosw 66:876-887

9. Briana DD, Boutsikou T, Baka S, Boutsikou M, Stamati L, Hassiakos D, Gourgiotis D, Malamitsi-Puchner A (2012) Perinatal role of hepcidin and iron homeostasis in full-term intrauterine growth-restricted infants. Eur J Haematol 90:37-44

10. Rishi G, Wallace DF, Subramaniam VN (2015) Hepcidin: regulation of the master iron regulator. Biosci Rep 35(3):e00192 
11. Merle U, Fein E, Gehrke SG, Stremmel W, Kulaksiz H (2007) The iron regulatory peptide hepcidin is expressed in the heart and regulated by hypoxia and inflammation. Endocrinology 148:2663-2668

12. Chelchowska M, Laskowska-Klita T (2002) Effect of maternal smoking on some markers of iron status in umbilical cord blood. Adv Med Sci 47:235-240

13. Rasmussen S, Bergsjo P, Jacobsen G, Haram K, Bakketeig LS (2005) Haemoglobin and serum ferritin in pregnancy-correlation with smoking and body mass index. Eur J Obstet Gynecol Reprod Biol 123:27-34

14. Laskowska-Klita T, Chelchowska M, Oltarzewski M, Gajewska J, Ambroszkiewicz J (2010) The effect of tobacco smoking during pregnancy on birth mass on the basis of population studies - preliminary results. Przegl Lek 67:830-834

15. Wojtyła C, Głuszek $€$, Biliński P, Paprzycki P, Warzocha K (2012) Smoking during pregnancy-hematological observations in pregnant women and their newborns after delivery. Ann Agricultural Environ Med 19(4):836-841

16. Sazak S, Kayiran SM, Paksoy Y (2012) Umbilical cord serum erythropoietin levels and maternal smoking during pregnancy. Sci World J. doi:10.1100/2012/420763

17. Teramo KA, Widness JA (2009) Increased fetal plasma and amniotic fluid erythropoietin concentrations: markers of intrauterine hypoxia. Neonatology 95:105-116

18. Pateva IB, Kerling EH, Reddy M, Chen D, Carlson SE, Tancabelic J (2015) Effect of maternal cigarette smoking on newborn iron stores. Clin Res Trials 1(1):4-7

19. Spencer K, Cowans NJ (2013) Accuracy of self-reported smoking status in first trimester aneuploidy screening. Prenat Diagn 33:116123

20. Habek D, Habek JC, Ivanisevic M, Djelmis J (2002) Fetal tobacco syndrome and perinatal outcome. Fetal Diagn Ther 17(6):367-371

21. Nilsen ST, Sagen N, Kim HC, Bergsjo P (1984) Smoking, hemoglobin levels, and birth weights in normal pregnancies. Am J Obstet Gynecol 148(6):752-758

22. Zafar J, Mohammad KN, Nisar M, Rashida M, Assadullah SB, Mohammad SA (2003) Effect of cigarette smoking on erythrocytes, leukocytes and haemoglobin. J Med Sci 3(3):245-250

23. Tamura T, Goldenberg R, Johnston K, DuBard MB (1995) Effect of smoking on plasma ferritin concentrations in pregnant women. Clin Chem 41:1190-1191

24. Dao MC, Sen S, Iyer C, Klebenov D, Meydani SN (2013) Obesity during pregnancy and fetal iron status: is hepcidin the link? 33(3): 177-181

25. Simvali S, Derbent AU, Uysal S, Turhan NO (2014) Hepcidin, iron status, and inflammation variables among healthy pregnant women in the Turkish population. J Matern Fetal Neonatal Med 27(1):7579

26. Young MF, Griffin I, Pressman E, McIntyre AW, Cooper E, McNanley T, Harris LZ, Westerman M, O'Brien KO (2011) Maternal hepcidin is associated with placental transfer of iron derived from dietary heme and nonheme sources. J Nutr 12:33-39

27. Van Santen S, de Mast Q, Luty AJF, Wiegerinck ET, Van der Ven AJ, Swinkels DW (2011) Iron homeostasis in mother and child during placental malaria infection. AmJTrop Med Hyg 84(1):148151

28. Van Santen S, Kroot JJ, Zijderveld G, Wiegerinck ET, Spaanderman ME, Swinkels DW (2013) The iron regulatory hormone hepcidin is decreased in pregnancy: a prospective longitudinal study. Clin Chem Lab Med 51(7):1395-1401

29. Finkensted A, Widschwendter A, Brasse-Lagnel CG, Theurl I, Hunalek M, Dieplinger H, Tselepis C, Ward DG, Vogel W, Zoller $\mathrm{H}$ (2012) Hepcidin is correlated to soluble hemojuvelin but not to increased GDF15 during pregnancy. Blood Cells Mol Dis 48:233237
30. Rehu M, Punnonen K, Ostland V, Heinonen S, Westerman M (2010) Maternal serum hepcidin is slow at term and independent of cord blood iron status. Eur J Haematol 85:345-352

31. Hedengran KK, Nelson D, Andersen MR, Stender S, Szecsi PB (2015) Hepcidin level are low during pregnancy and increase around delivery in women without iron deficiency - a prospective cohort study. J Matern Fetal Neonatal Med 29:1-3

32. Gyarmati B, Szabo E, Szalay B, Czuczy N, Toldi G, Cseh A, Vasarhelyi B, Takats Z (2011) Serum maternal hepcidin levels 3 days after delivery are higher compared to those measured at parturition. J Obstet Gynaecol Res 37(11):1620-1624

33. Chelchowska M, Lewandowski L, Ambroszkiewicz J, Swiatek E, Gajewska J, Ołtarzewski M, Laskowska-Klita T (2008) The effect of tobacco smoking during pregnancy on concentration of prohepcidin and some parameters of iron metabolism in matchedmaternal cord pairs. Przegl Lek 65(10):474-478

34. Casanueva E, Viteri FE (2003) Iron and oxidative stress in pregnancy. J Nutr 133:1700S-1708S

35. Attia A, Mohammed T, Al Aziz U (2015) The relationship between serum hepcidin level and hypoxemia in the CODP patients. Egyp Soc Chest Dis Tuber 65:57-61

36. Ravasi J, Pelucchi S, Greni F, Mariani R, Giuliano A, Parati G, Silvestri L, Piperno A (2014) Circulating factors are involved in hypoxia-induced hepcidin suppression. Blood Cells Mol Dis 53: 204-210

37. Amarilyo G, Mimouni FB, Oren A, Ochshorn Y, Ballin A, Deutsch V, Mandel D (2010) Prohepcidin concentrations and erythroid progenitors in cord blood of appropriate versus small for gestational age neonates. J Perinat 30:396-398

38. Ozkiraz S, Kilicdag H, Gokmen Z, Ecevit A, Tarcan A, Ozbek N (2011) Serum prohepcidin levels and iron parameters in term smallfor-gestational-age newborn. J Matern Fetal Neonatal Med 24(12): $1437-1439$

39. Nicolas G, Chauvet C, L. V, JL D, Bigard X, Devaux I, Beaumont C, Kahn A, Vaulont S (2002) The gene encoding the iron regulatory peptide hepcidin is regulated by anemia, hypoxia, and inflammation. J Clin Invest 110:1037-1044

40. Choi SO, Cho YS, Kim HL, Park JW (2007) ROS mediate the hypoxic repression of the hepcidin gene by inhibiting $\mathrm{C} /$ EBPalpha and STAT-3. Biochem Biophys Res Commun 356: 312-317

41. Andersen MR, Simonsen U, Uldbjerg N, Aalkjaer C, Stender S (2009) Smoking cessation early in pregnancy and birth weight, length, head circumference, and endothelial nitric oxide synthase activity in umbilical and chorionic vessels: an observational study of healthy singleton pregnancies. Circulation 119:857-864

42. Rogers J (2009) Tobacco and pregnancy. Reprod Toxicol 28:152160

43. Król M, Florek E, Kornacka MK, Bokiniec R, Piekoszewski W (2009) Clinical condition of the newborn versus tobacco smoke exposure during fetal life. Przegl Lek 66(10):548-553

44. Rao R, Georgieff MK (2007) Iron in fetal and neonatal nutrition. Semin Fetal Neonatal Med 12(1):54-63

45. Alwan AN, Cade JE, McArdle HJ, Greenwood DC, Hayes HE, Simpson NA (2015) Maternal iron status in early pregnancy and birth outcomes: insight from the baby's vascular health and iron in pregnancy study. Br J Nutr 113:1985-1992

46. Meberg A, Haga P, Sande H, Foss OP (1979) Smoking during pregnancy hematological observations in the newborn. Acta Paediatr Scand 68:731-734

47. Sweet DG, Savage G, Tuhman TR, Lappin TR, Halliday HL (2001) Study of maternal influences on fetal iron status at term using cord blood transferrin receptors. Arch Dis Child 84:40-43

48. Kong WN, Niu QM, Ge L, Zhang N, Yan SF, Chen WB, Chang YZ, Zhao SE (2014) Sex differences in iron status and hepcidin expression in rat. Biol Trace Elem Res 160:258-267 